\title{
Evaluation of Three Field Rewarming Techniques During Cold Weather Military Training
}

\author{
Douglas Jones, $\mathrm{PhD}^{1,2}$; Justin Bowles, $\mathrm{MD}^{3}$; Dale Bergquist-Turori, MS ${ }^{1,2}$; Christina Cooper, MS ${ }^{1,2}$; \\ Kaitlyn Rostomily, $\mathrm{MS}^{1,2}$; Carina Pautz, $\mathrm{MS}^{4}$; Jay Heaney, MA ${ }^{2}$ \\ ${ }^{1}$ Leidos, Inc., San Diego, CA; ${ }^{2}$ Warfighter Performance Department, Naval Health Research Center, San Diego, CA; ${ }^{3}$ Marine Corps Mountain Warfare \\ Training Center, Bridgeport, CA; ${ }^{4}$ Innovative Employee Solutions, San Diego, CA
}

\begin{abstract}
Introduction-The purpose of this work was to evaluate the effectiveness of 3 rewarming techniques to determine how warfighters, and perhaps other populations in wilderness environments, should prioritize field rewarming options after a brief accidental immersion in cold water.

Methods - As part of a cold weather military training exercise, 31 military personnel (mean \pm SD age: $26 \pm$ $5 \mathrm{y}$, height: $180 \pm 10 \mathrm{~cm}$, weight: $83.2 \pm 10.9 \mathrm{~kg})$ completed a 10 -min immersion in cold $\left(0^{\circ} \mathrm{C}\right)$ water and subsequently rewarmed for 60 min using 3 different field rewarming techniques (sleeping bag, sleeping bag + warm fluids, or exercise). Heart rate, core and skin temperatures, thermal and shivering sensations, and manual dexterity (intravenous setup and insertion) were measured during the training exercise.

Results-Cold water immersion decreased core temperature (pre: $37.4 \pm 0.4$; post: $36.4 \pm 1.0^{\circ} \mathrm{C} ; P<0.001$ ) and mean skin temperature (pre: $27.9 \pm 1.3$; post: $15.6 \pm 1.8^{\circ} \mathrm{C} ; P<0.001$ ) and impaired manual dexterity (intravenous insertion time, pre: $71 \pm 12$, post: $166 \pm 48 \mathrm{~s} ; P<0.001$ ). Recovery from mild cold stress was similar among all 3 rewarming techniques for all measurements.

Conclusions-Findings suggesting similar rewarming responses in field settings are beneficial for the warfighter, and perhaps others, in that rewarming options exist and can be implemented with no compromise in recovery from cold stress.
\end{abstract}

Keywords: cold stress, immersion, performance, warfighter, rewarm, wilderness

\section{Introduction}

Accidental cold water immersion presents several challenges for those venturing into remote wilderness settings, ranging from minor inconveniences to full-scale rescue efforts to recover body temperature and preserve life. ${ }^{1}$ Among warfighters specifically (ie, sailors, soldiers, and Marines), accidental immersion impairs operational performance and deteriorates mission readiness. ${ }^{2}$ Fortunately, military leaders often require their warfighters to train for accidental cold water immersion. They are taught to anticipate the cold shock response, control breathing to avoid

Corresponding author: Douglas Jones, $\mathrm{PhD}$, Naval Health Research Center, Warfighter Performance Department, 140 Sylvester Rd, San Diego, CA 92106; e-mail: douglas.m.jones@leidos.com.

Submitted for publication October 2019.

Accepted for publication April 2020. hyperventilation, self-extricate after falling through ice, and rewarm in the field using various techniques. ${ }^{3-5}$

Rewarming in wilderness settings may include spontaneous rewarming (ie, shivering), body-to-body warming, ingestion of warm fluids, and exercise, among others. ${ }^{6,7}$ Reasons for implementing different rewarming techniques depend on situational variables, such as cold stress severity, equipment availability, weather conditions, and, for the warfighter, the presence of hostile forces. The success of rewarming is often measured using core temperature, which can be difficult to accurately assess in combat or wilderness settings. ${ }^{8}$ Other indicators such as mental status and functional performance may need to be used in operational settings to evaluate recovery from accidental cold water immersion.

The Marine Corps Mountain Warfare Training Center (MCMWTC), located in Bridgeport, California, conducts cold weather field training exercises in environments that are likely to be encountered by warfighters. These training 
environments offer unique opportunities to gather important information on warfighter recovery after cold water immersion. Given the scarcity of literature on rewarming investigations conducted in field settings, evaluation of the efficacy of rewarming techniques in actual conditions encountered by warfighters is needed. The purpose of this work was to evaluate the effectiveness of 3 rewarming techniques used by Marine Corps personnel to determine how warfighters, and perhaps other populations in wilderness environments, should prioritize field rewarming options after a brief accidental immersion in cold water. Of the rewarming techniques used, it was hypothesized that exercise, and not spontaneous rewarming (with or without warm fluid ingestion), would provide a stronger stimulus for overall rewarming success.

\section{Methods}

\section{RESEARCH PARTICIPANTS}

Active duty military members were recruited to participate in this study. Per course requirements, students enrolled in MCMWTC's cold weather medicine course were required to participate in immersion and rewarming training exercises to successfully complete the course. Therefore, only students enrolled in this course were recruited to participate.

\section{STUDY DESIGN}

During the immersion and rewarming training exercise, participants moved through different phases with fixed times for each phase. Phases were defined as "pre" (before entering water; $5 \mathrm{~min}$ ), "immersion" (water immersion to neck; $10 \mathrm{~min}$ ), "post" (after exiting water; $5 \mathrm{~min}$ ), "start rewarm" (start of 60 min rewarming), and "end rewarm" (end of 60 min rewarming). MCMWTC medical staff monitored participants' core temperature $\left(\mathrm{T}_{\mathrm{c}}\right)$, mean skin temperature $\left(\bar{T}_{\mathrm{sk}}\right)$, and heart rate (HR) throughout each phase using ingestible temperature pills, dermal temperature patches, and HR monitors, respectively. Those who chose to participate in the study provided voluntary informed consent to 1) allow their body temperature and HR recordings to be aggregated and analyzed for research purposes; 2) complete a manual dexterity task; and 3 ) provide ratings of temperature and shivering sensations. The study was approved by the Naval Health Research Center's institutional review board (protocol \# NHRC.2015.0009).

\section{BODY TEMPERATURE, HEART RATE, AND TEMPERATURE SENSATIONS}

Ingestible $\mathrm{T}_{\mathrm{c}}$ pills (Respironics, Bend, $\mathrm{OR}$ ) were administered to participants by MCMWTC staff approximately 8 $\mathrm{h}$ before the start of the immersion and rewarming training exercise. Skin temperature patches (Respironics) were affixed to the chest (centered over the pectoralis major), shoulder (lateral aspect of the right deltoid, slightly above the lateral head of the triceps), thigh (mid-thigh; centered over the rectus femoris), and calf (centered over the gastrocnemius). $\bar{T}_{\text {sk }}$ was calculated using the Ramanathan equation. ${ }^{9} \mathrm{~T}_{\mathrm{c}}, \bar{T}_{\mathrm{sk}}$, and HR (Polar Electro, Lake Success, $\mathrm{NY}$ ) were electronically recorded each minute during the training exercise. Ratings of thermal sensation (TS; ranging from $-4=$ very cold to $+4=$ very hot) and shivering sensation (SS; ranging from $0=$ no shivering to $3=$ vigorous shivering) were collected in each phase (pre, immersion, post, start rewarm, end rewarm). TS and SS charts, often used in cold water immersion research, were visually presented, and participants verbally responded with their ratings. ${ }^{10,11}$

\section{OPERATIONAL TASK}

Operational performance was assessed at pre, post, and end rewarm using a manual dexterity task. Participants were given $5 \mathrm{~min}$ to complete an intravenous (IV) insertion on a manikin arm (Nasco, Fort Atkinson, WI). Six steps were required for IV insertion and consisted of 1) puncturing IV bag, 2) flushing IV line, 3) closing in-line clamp, 4) placing tourniquet on manikin arm, 5) performing needle stick into median cubital vein of manikin arm, and 6) opening inline clamp (simulating fluid infusion). Participants were allowed 1 attempt to reposition the needle to ensure successful insertion into the vein. Research staff recorded the accuracy of the required steps and the total time to complete the IV insertion (successful insertion confirmed by research staff based on "red flash" of artificial blood). All participants were current military medical providers, were familiar with IV insertion techniques, and were given ample time to practice the steps and techniques before beginning the task.

\section{REWARMING}

After immersion, participants completed $5 \mathrm{~min}$ at post and then changed into dry clothing. After donning dry clothing, they were randomly assigned to 1 of 3 rewarming groups, which consisted of 1) entering a sleeping bag (SB), 2) entering a sleeping bag and consuming $1 \mathrm{~L}$ of warm broth during $60 \mathrm{~min}(\mathrm{SB}+\mathrm{F})$, or 3$)$ completing 12 rounds of an exercise circuit (EX). Exercises consisted of 20 body weight squats, 20 jumping jacks, 20 push-ups, and 20 bicycle kicks (completed on a deck free of snow and ice). Participants completed each round of exercises every $5 \mathrm{~min}$.

\section{STATISTICAL ANALYSIS}

The effects of cold water immersion were determined using a repeated-measures analysis of variance (ANOVA) to 
Table 1. Demographic information (mean \pm SD) for all participants and each rewarming group.

\begin{tabular}{llllll}
\hline & $\begin{array}{l}\text { Age } \\
(\mathrm{y})\end{array}$ & $\begin{array}{l}\text { Height } \\
(\mathrm{cm})\end{array}$ & $\begin{array}{l}\text { Weight } \\
(\mathrm{kg})\end{array}$ & $\begin{array}{l}\mathrm{BMI} \\
\left(\mathrm{kg} \cdot \mathrm{m}^{-2}\right)\end{array}$ \\
\hline SB & 10 & $27 \pm 6$ & $184 \pm 5$ & $85.7 \pm 10.6$ & $25.2 \pm 2.8$ \\
SB+F & 11 & $26 \pm 6$ & $174 \pm 13$ & $78.4 \pm 10.2$ & $26.1 \pm 3.0$ \\
EX & 10 & $24 \pm 4$ & $182 \pm 6$ & $87.8 \pm 13.4$ & $26.4 \pm 3.5$ \\
Total & 31 & $26 \pm 5$ & $180 \pm 10$ & $83.2 \pm 10.9$ & $25.9 \pm 3.1$ \\
\hline
\end{tabular}

$\mathrm{SB}$, sleeping bag; $\mathrm{SB}+\mathrm{F}$, sleeping bag+warm fluids; $\mathrm{EX}$, exercise.

analyze $\mathrm{T}_{\mathrm{c}}, \bar{T}_{\mathrm{sk}}, \mathrm{HR}$, TS, and $\mathrm{SS}$ at pre, immersion, and post. A paired-samples t-test was used to analyze the impact of cold water immersion on IV insertion time (pre vs post). Rewarming efficacy was determined using 1-way ANOVA to compare rewarming groups $(\mathrm{SB}, \mathrm{SB}+\mathrm{F}, \mathrm{EX})$ at start rewarm and end rewarm and by comparing the changes in values (ie, deltas) from start rewarm to end rewarm. Rewarming effects on IV insertion time were analyzed using 1-way ANOVA to compare rewarming groups ( $\mathrm{SB}$, $\mathrm{SB}+\mathrm{F}, \mathrm{EX}$ ) at post and end rewarm and by comparing the changes in values from post to end rewarm. Bonferroni corrections were used for post hoc tests, with a significance level set at $P<0.05$. Data are presented as means \pm SD.

\section{Results}

\section{PARTICIPANTS}

Thirty-one active duty military members (30 male, 1 female) participated in this study and self-reported their age, height, weight, and body mass index (Table 1).

\section{ENVIRONMENTAL CONDITIONS}

The immersion and rewarming exercise began at 0700 onsite at the MCMWTC (2100 m altitude). A small pond was used for immersion. At the start of the exercise, ambient environmental conditions were as follows: air temperature $\left(-5^{\circ} \mathrm{C}\right)$, wind speed $\left(0 \mathrm{~m} \cdot \mathrm{s}^{-1}\right)$, and water temperature $\left(0^{\circ} \mathrm{C}\right)$. Participants wore military clothing consisting of utility uniforms ( $\mathrm{t}$-shirt, blouse, trousers, socks, and athletic shoes).

\section{EFFECTS OF COLD WATER IMMERSION}

Cold water immersion significantly influenced all measurements (Table 2). Specifically, cold water immersion decreased $\mathrm{T}_{\mathrm{c}} \quad(P<0.001), \bar{T}_{\mathrm{sk}} \quad(P<0.001)$, and $\mathrm{TS}$ $(P<0.001)$ and increased HR $(P<0.01)$, SS $(P<0.001)$, and IV insertion time $(P<0.001)$.
Table 2. Physiological, perceptual, and dexterity responses $($ mean \pm SD) for pre, immersion, and post

\begin{tabular}{llll}
\hline & Pre & Immersion & Post \\
\hline $\mathrm{T}_{\mathrm{c}}\left({ }^{\circ} \mathrm{C}\right)$ & $37.4 \pm 0.4^{b}$ & $37.0 \pm 0.5^{a}$ & $36.4 \pm 0.9^{a, b}$ \\
$\bar{T}_{\text {sk }}\left({ }^{\circ} \mathrm{C}\right)$ & $27.9 \pm 1.3^{b}$ & $13.6 \pm 1.7^{a}$ & $15.6 \pm 1.8^{a, b}$ \\
$\mathrm{HR}\left(\right.$ beats $\left.\cdot \mathrm{min}^{-1}\right)$ & $98 \pm 11^{b}$ & $105 \pm 14^{a}$ & $106 \pm 14^{a}$ \\
$\mathrm{TS}$ & $-1.3 \pm 1.2^{b}$ & $-3.6 \pm 0.9^{a}$ & $-3.5 \pm 1.0^{a}$ \\
$\mathrm{SS}$ & $0.5 \pm 0.6^{b}$ & $1.5 \pm 1.1^{a}$ & $1.5 \pm 1.0^{a}$ \\
IV insertion time (s) & $71 \pm 12$ & --- & $166 \pm 48^{a}$ \\
\hline
\end{tabular}

$\mathrm{HR}$, heart rate; $\mathrm{SS}$, shivering sensation; $\mathrm{T}_{\mathrm{c}}$, core temperature; $\bar{T}_{\mathrm{sk}}$, mean skin temperature; TS, thermal sensation.

${ }^{\text {a }}$ Different from pre $(P<0.05)$.

${ }^{\mathrm{b}}$ Different from immersion $(P<0.05)$.

\section{REWARMING EVALUATION}

Rewarming groups were compared at start rewarm and end rewarm for each measurement. The change from start rewarm to end rewarm was also compared between groups for each measurement (Table 3). There were no differences among groups at start rewarm for $\mathrm{T}_{\mathrm{c}}(P=0.807), \bar{T}_{\mathrm{sk}}(P=$ $0.284)$, HR $(P=0.813)$, TS $(P=0.782)$, and SS $(P=0.623)$. IV insertion time was not assessed at start rewarm, so groups were evaluated on their performance at post; there were no differences in IV insertion time among the groups $(P=0.233)$. At end rewarm, no differences among groups were observed for $\mathrm{T}_{\mathrm{c}}(P=0.667), \bar{T}_{\text {sk }}(P=0.076)$, TS $(P=$ $0.381)$, SS $(P=0.127)$, and IV insertion time $(P=0.787)$. However, HR was elevated in EX compared with SB and $\mathrm{SB}+\mathrm{F}$ at end rewarm $(P<0.001)$. Similar results were observed when comparing the change from start rewarm to end rewarm in that there were no differences among groups for $\mathrm{T}_{\mathrm{c}}(P=0.539), \bar{T}_{\mathrm{sk}}(P=0.092)$, TS $(P=0.668)$, SS $(P=0.861)$, and IV insertion time $(P=0.222)$.

\section{Discussion}

This study evaluated the effectiveness of 3 rewarming techniques to determine how field rewarming should be prioritized in operational and other settings after a brief immersion in cold water. Findings indicate that 1) participants were mildly cold-stressed from cold water immersion and cold air exposure and 2) rewarming responses were similar among all rewarming groups for all measurements ( $\mathrm{T}_{\mathrm{c}}, \bar{T}_{\mathrm{sk}}$, TS, SS, IV insertion time). Our hypothesis that exercise would facilitate superior rewarming success, as measured by $\mathrm{T}_{\mathrm{c}}, \bar{T}_{\mathrm{sk}}$, TS, SS, and IV insertion time, is not supported. These findings do suggest, however, that several rewarming options with similar outcomes are available for those who experience a brief immersion in cold water. 
Table 3. Physiological, perceptual, and dexterity responses (mean \pm SD) for start rewarm, end rewarm, and the difference $(\Delta)$ between start rewarm and end rewarm

\begin{tabular}{|c|c|c|c|c|c|}
\hline & $n$ & Post & Start Rewarm & End Rewarm & $\Delta$ \\
\hline$S B$ & 10 & & & & \\
\hline $\mathrm{T}_{\mathrm{c}}\left({ }^{\circ} \mathrm{C}\right)$ & & --- & $35.8 \pm 1.4$ & $36.8 \pm 0.4$ & $1.0 \pm 1.2$ \\
\hline $\bar{T}_{\text {sk }}\left({ }^{\circ} \mathrm{C}\right)$ & & --- & $17.4 \pm 1.3$ & $31.4 \pm 1.5$ & $14.0 \pm 1.1$ \\
\hline HR (beats $\cdot \min ^{-1}$ ) & & --- & $110 \pm 19$ & $92 \pm 10$ & $-18 \pm 12$ \\
\hline $\mathrm{TS}$ & & --- & $-3.2 \pm 0.6$ & $0.1 \pm 1.4$ & $3.3 \pm 1.6$ \\
\hline $\mathrm{SS}$ & & --- & $2.1 \pm 0.6$ & $0.1 \pm 0.3$ & $-2.0 \pm 0.7$ \\
\hline IV insertion time (s) & & $177 \pm 53$ & --- & $77 \pm 13$ & $-100 \pm 44$ \\
\hline$S B+F$ & 11 & & & & \\
\hline $\mathrm{T}_{\mathrm{c}}\left({ }^{\circ} \mathrm{C}\right)$ & & --- & $36.1 \pm 0.5$ & $36.7 \pm 1.0$ & $0.6 \pm 1.0$ \\
\hline $\bar{T}_{\mathrm{sk}}\left({ }^{\circ} \mathrm{C}\right)$ & & --- & $18.7 \pm 2.3$ & $31.9 \pm 1.5$ & $13.2 \pm 2.0$ \\
\hline HR (beats $\cdot \min ^{-1}$ ) & & --- & $112 \pm 14$ & $98 \pm 9$ & $-14 \pm 15$ \\
\hline TS & & --- & $-3.0 \pm 1.5$ & $0.0 \pm 1.7$ & $3.0 \pm 1.8$ \\
\hline SS & & & $2.4 \pm 0.7$ & $0.5 \pm 0.8$ & $-1.9 \pm 0.8$ \\
\hline IV insertion time (s) & & $142 \pm 39$ & --- & $72 \pm 19$ & $-69 \pm 28$ \\
\hline$E X$ & 10 & & & & \\
\hline $\mathrm{T}_{\mathrm{c}}\left({ }^{\circ} \mathrm{C}\right)$ & & --- & $35.9 \pm 1.4$ & $37.0 \pm 0.8$ & $1.1 \pm 1.0$ \\
\hline $\bar{T}_{\text {sk }}\left({ }^{\circ} \mathrm{C}\right)$ & & --- & $18.2 \pm 1.6$ & $30.4 \pm 1.0$ & $12.2 \pm 1.6$ \\
\hline HR (beats $\cdot \min ^{-1}$ ) & & --- & $107 \pm 20$ & $122 \pm 15^{a, b}$ & $15 \pm 12^{a, b}$ \\
\hline $\mathrm{TS}$ & & --- & $-2.8 \pm 1.4$ & $0.9 \pm 1.6$ & $3.7 \pm 1.8$ \\
\hline SS & & --- & $2.1 \pm 0.9$ & $0.0 \pm 0.0$ & $-2.1 \pm 0.9$ \\
\hline IV insertion time (s) & & $175 \pm 48$ & --- & $76 \pm 13$ & $-98 \pm 46$ \\
\hline
\end{tabular}

EX, exercise; HR, heart rate; $\mathrm{SB}$, sleeping bag; $\mathrm{SB}+\mathrm{F}$, sleeping bag+warm fluids; $\mathrm{SS}$, shivering sensation; $\mathrm{T}_{\mathrm{c}}$, core temperature; $\bar{T}_{\text {sk }}$, mean skin temperature; TS, thermal sensation.

${ }^{a}$ Different from SB $(P<0.05)$.

b Different from $\mathrm{SB}+\mathrm{F}(P<0.05)$.

Cold water immersion severity, and the ensuing rate of body heat loss, is highly dependent on variables such as water temperature and movement, immersion duration, thermal protection, and depth of immersion (ie, partial vs full). ${ }^{12-15}$ In the current study, a 10-min immersion to the neck in a static, cold pond with minimal thermal protection lowered body temperature and caused participants to feel colder and perceive greater shivering. The immersion also deteriorated performance in a manual dexterity task; time to complete an IV after immersion took more than twice as long as before immersion. Deterioration of manual dexterity is expected with the skin temperatures reported, considering dexterity loss is noted by others when hand temperatures fall below $15^{\circ} \mathrm{C} .{ }^{16,17}$ Although not measured in the current study, it is likely that hand temperatures were reduced below $15^{\circ} \mathrm{C}$, given the observed $\bar{T}_{\text {sk }}$ of $15.6^{\circ} \mathrm{C}$. In light of such changes in physiology, perception, and task performance resulting from immersion in cold water and exposure to cold air, field rewarming is indicated to arrest further deterioration and facilitate recovery.

Investigations evaluating the efficacy of actual field rewarming are scarce, ${ }^{18}$ but controlled laboratory studies suggest no difference in recovery times from hypothermia using spontaneous rewarming (shivering), exercise (treadmill walking), or external heat application. ${ }^{19}$ Using cold water immersion, Giesbrecht et al. cooled participants to $\mathrm{T}_{\mathrm{c}} 33^{\circ} \mathrm{C}$ and subsequently evaluated $\mathrm{T}_{\mathrm{c}}$ recovery. They noted a large $T_{c}$ afterdrop with exercise but found no final differences between shivering or external heat application rewarming techniques. Similar to findings from the current study, all 3 rewarming techniques provided a similar recovery. ${ }^{19}$ Rewarming rates reported in the literature for shivering and exercise are 3 to $4^{\circ} \mathrm{C} \cdot \mathrm{h}^{-1}$ and $5^{\circ} \mathrm{C} \cdot \mathrm{h}^{-1}$, respectively, ${ }^{7,20,21}$ but this assumes hypothermia and not mild cold stress. In the case of mild cold stress, we report rewarming rates of only $1^{\circ} \mathrm{C} \cdot \mathrm{h}^{-1}$ for both shivering and exercise. Hence, the stimulus for faster rewarming rates appears to be influenced by lower $\mathrm{T}_{\mathrm{c}}$. Several concerns are raised when using exercise as a rewarming option in moderate to severe hypothermia in that the risk of cardiac irritability increases along with both time and magnitude of afterdrop. ${ }^{22,23}$ These concerns, however, are rarely raised for individuals who have only experienced mild cold stress. Exercise therefore remains a viable option for those who experience mild cold stress resulting from cold water immersion. 
Warfighters represent a unique population; their actions for cold stress recovery could be highly dictated by dynamic military situations. For example, warfighters may not have the freedom to exercise in the open or access to stoves for heating warm broth. Instead, they may be engaged with hostile forces or require covertness to remain undetected. ${ }^{24,25}$ Findings suggesting similar rewarming responses in field settings therefore are beneficial for the warfighter, and perhaps others, in that options exist and can be implemented with no compromise in recovery from cold stress.

\section{LIMITATIONS}

Several limitations are present in the current study that require attention. The population studied consisted of primarily young male military personnel. All were fit for full duty and aware of the procedures that would take place during the field training exercise. In true accidental immersion, health status and age can vary greatly and victims are likely unaware of impending immersion, which may negatively influence physiologic and psychological responses to cold water immersion. ${ }^{26-28}$ Additionally, recommendations for field rewarming are typically focused on recovery from hypothermia and not mild cold stress. Although several participants did experience hypothermia, rewarming procedures started with each group near $\mathrm{T}_{\mathrm{c}} 36.0^{\circ} \mathrm{C}$. Had rewarming been evaluated from a $\mathrm{T}_{\mathrm{c}}$ below $35^{\circ} \mathrm{C}$, it is possible that the rewarming outcomes may have differed. Large variations in $\mathrm{T}_{\mathrm{c}}$ were also observed in this population and are likely attributed to individual differences in subcutaneous fat amounts, vasoconstrictor and blood flow responses, and metabolic heat production. ${ }^{29,30}$ It is not anticipated that variations in $T_{c}$ would greatly influence IV insertion time because dexterity performance is related more to finger/hand temperature and less to $\mathrm{T}_{\mathrm{c}} \cdot{ }^{31}$ For the EX rewarming group, exercises such as jumping jacks, bicycle kicks, and squats used at frequent intervals during rewarming included large muscle groups. However, it is possible that other exercise types and intensities could influence rewarming rates, and this should be taken into consideration in future investigations. ${ }^{32}$ Lastly, warm broth provided to students was heated, but the temperature or timing of ingestion was not measured. This, too, could have influenced rewarming rates for the $\mathrm{SB}+\mathrm{F}$ group.

\section{Conclusions}

The Wilderness Medical Society recently published clinical practice guidelines for hypothermia and addressed field rewarming recommendations. ${ }^{6}$ Strong recommendations for shivering, shivering with ingestion of warm fluids, and exercise were presented, with shivering supported by high-quality evidence and shivering with ingestion of warm fluids and exercise supported by low-quality evidence. Findings from the current study, perhaps only relevant to mild cold stress and not true hypothermia, add to this growing body of knowledge and indicate that body temperature, perceptual measurements of temperature and shivering, and functional performance recover similarly among different field rewarming techniques.

Acknowledgments: The authors thank the staff at the Marine Corps Mountain Warfare Training Center for their support during this study.

Author Contributions: Study concept and design (DJ, JB, JH); acquisition of the data (DJ, DB, CC, KR, CP, JH); analysis of the data (DJ, $\mathrm{DB}, \mathrm{CC}, \mathrm{KR}, \mathrm{CP}$ ); drafting of the manuscript (DJ); critical revision of the manuscript (JB, JH); approval of final manuscript (DJ, JB, DB-T, CC, $\mathrm{KR}, \mathrm{CP}, \mathrm{JH})$.

Financial/Material Support: This study was supported by the US Navy Bureau of Medicine and Surgery under work unit no. N1804.

Disclosures: None.

\section{References}

1. Gilbert M, Busund R, Skagseth A, Nilsen PA, Solbø JP. Resuscitation from accidental hypothermia of 13.7 degrees C with circulatory arrest. Lancet. 2000;355(9201):375-6.

2. Wittmers L, Savage M. Cold water immersion. In: Pandolf KB, Burr RE, eds. Medical Aspects of Harsh Environments. Washington, DC: Borden Institute; 2001:532.

3. Feith S, Hesslink R, Reading J, Kincaid P, Pozos RS. Rewarming methodologies in the field (No. NHRC-93-4). San Diego, CA: Naval Health Research Center; 1993.

4. Pozos RS, Danzl D. Human physiological responses to cold stress and hypothermia. Medical Aspects of Harsh Environments. 2001;1:351-82.

5. Tipton M. The initial responses to cold-water immersion in man. Clin Sci (Lond). 1989;77(6):581-8.

6. Dow J, Giesbrecht GG, Danzl DF, Brugger H, Sagalyn EB, Walpoth B, et al. Wilderness Medical Society clinical practice guidelines for the out-of-hospital evaluation and treatment of accidental hypothermia: 2019 update. Wilderness Environ Med. 2019;30(4S):S47-69.

7. Giesbrecht GG. Cold stress, near drowning and accidental hypothermia: a review. Aviat Space Environ Med. 2000;71(7):733-52.

8. Rathjen NA, Shahbodaghi SD, Brown JA. Hypothermia and cold weather injuries. Am Fam Physician. 2019;100(11): 680-6.

9. Ramanathan N. A new weighting system for mean surface temperature of the human body. J Appl Physiol. 1964;19: $531-3$.

10. Brazaitis M, Eimantas N, Daniuseviciute L, Baranauskiene N, Skrodeniene E, Skurvydas A. Time course of physiological and psychological responses in humans during a 20-day severe-cold-acclimation programme. PLoS One. 2014;9(4), e94698.

11. Jones DM, Rostomily KA, Pautz CM, Ito DW, Bailey SP, Roelands B, et al. Cold acclimation does not alter 
physiological or perceptual responses during subsequent exercise in the heat. Mil Med. 2017;182(9):e1958-64.

12. Hayward JS. Thermal protection performance of survival suits in ice-water. Aviat Space Environ Med. 1984;55(3): 212-5.

13. Peiffer JJ, Abbiss CR, Watson G, Nosaka K, Laursen PB. Effect of cold-water immersion duration on body temperature and muscle function. J Sports Sci. 2009;27(10):987-93.

14. Vieira A, Siqueira AF, Ferreira-Júnior JB, do Carmo J, Durigan JL, Blazevich A, et al. The effect of water temperature during cold-water immersion on recovery from exercise-induced muscle damage. Int J Sports Med. 2016;37(12):937-43.

15. Lee DT, Toner MM, McArdle WD, Vrabas IS, Pandolf KB. Thermal and metabolic responses to cold-water immersion at knee, hip, and shoulder levels. J Appl Physiol (1985). 1997;82(5):1523-30.

16. Heus R, Daanen HA, Havenith G. Physiological criteria for functioning of hands in the cold: a review. Appl Ergon. 1995;26(1):5-13.

17. Cheung SS, Montie DL, White MD, Behm D. Changes in manual dexterity following short-term hand and forearm immersion in 10 degrees C water. Aviat Space Environ Med. 2003;74(9):990-3.

18. Rogers I. Which rewarming therapy in hypothermia? A review of the randomised trials. Emerg Med. 1997;9(3): $213-20$.

19. Giesbrecht GG, Bristow GK, Uin A, Ready AE, Jones RA. Effectiveness of three field treatments for induced mild (33.0 degrees C) hypothermia. J Appl Physiol (1985). 1987;63(6):2375-9.

20. Giesbrecht GG, Bristow GK. The convective afterdrop component during hypothermic exercise decreases with delayed exercise onset. Aviat Space Environ Med. 1998;69(1):17-22.

21. Haman F, Scott CG, Kenny GP. Fueling shivering thermogenesis during passive hypothermic recovery. J Appl Physiol (1985). 2007;103(4):1346-51.
22. Hanania NA, Zimmerman JL. Accidental hypothermia. Crit Care Clin. 1999;15(2):235-49.

23. Mallet ML. Pathophysiology of accidental hypothermia. QJM. 2002;95(12):775-85.

24. Moran DS, Heled Y, Shani Y, Epstein Y. Hypothermia and local cold injuries in combat and non-combat situations the Israeli experience. Aviat Space Environ Med. 2003;74(3): 281-4.

25. Schmelz JO, Bridges EJ, Wallace MB, Sanders SF, Shaw T, Kester N, et al. Comparison of three strategies for preventing hypothermia in critically injured casualties during aeromedical evacuation. Mil Med. 2007;172(3):322-6.

26. Barwood MJ, Dalzell J, Datta AK, Thelwell RC, Tipton MJ. Breath-hold performance during cold water immersion: effects of psychological skills training. Aviat Space Environ Med. 2006;77(11):1136-42.

27. Barwood MJ, Corbett J, Wagstaff CR. Habituation of the cold shock response may include a significant perceptual component. Aviat Space Environ Med. 2014;85(2):167-71.

28. Tipton M, Eglin C, Golden F. Habituation of the initial responses to cold water immersion in humans: a central or peripheral mechanism? J Physiol. 1998;512(Pt 2): $621-8$.

29. Hayward MG, Keatinge WR. Roles of subcutaneous fat and thermoregulatory reflexes in determining ability to stabilize body temperature in water. J Physiol. 1981;320(1): 229-51.

30. Vaile J, O'Hagan C, Stefanovic B, Walker M, Gill N, Askew CD. Effect of cold water immersion on repeated cycling performance and limb blood flow. Br J Sports Med. 2011;45(10):825-9.

31. Havenith G, Heus R, Daanen HA. The hand in the cold, performance and risk. Arctic Med Res. 1995;54(S2): 37-47.

32. Rintamäki H, Hassi J, Oksa J, Mäkinen T. Rewarming of feet by lower and upper body exercise. Eur J Appl Physiol Occup Physiol. 1992;65(5):427-32. 